\title{
The laboratory animal legal system of China
}

\author{
Li-hong Gao* \\ Professor of Law School of Zhongnan University of Economics and Law \\ Vice President of China Society of Environmental Resources Law \\ President of Hubei Province Society of Environmental Resources Law
}

Recommended citation. GAO, L. The laboratory animal legal system of China, dA. Derecho Animal (Forum of Animal Law Studies) 11/2 (2020). - DOI https://doi.org/10.5565/rev/da.500

\begin{abstract}
The scale of laboratory animal production in China has been increasing year by year. For the purpose of standardizing management, protecting the welfare of laboratory animals, China has established a relatively complete legal system for them. China has also formulated legal concepts such as "laboratory animals", "laboratory animal welfare," and "cruelty to laboratory animals". Research and development of chemicals, drugs, food, and cosmetics are areas where animal experiments are legally required. The management model of laboratory animals can be summarized as government supervision and third-party certification management. The core pillar of government supervision is the licensing system and the certification system. China has also established a self-supervision system for laboratory animal institutions such as monitoring and ethical review. In the future, it should continue to improve the existing system and strengthen law enforcement.
\end{abstract}

Keywords: laboratory animal; legal system; animal welfare.

Resumen - El régimen jurídico de los animales de laboratorio de China

El volumen de producción de animales de laboratorio en China ha ido aumentando año tras año. Con el fin de estandarizar el manejo, protegiendo el bienestar de los animales de laboratorio, China ha establecido un régimen jurídico relativamente completo para ellos. China también ha formulado conceptos jurídicos como "animales de laboratorio", "bienestar de animales de laboratorio" y "crueldad hacia los animales de laboratorio". La investigación y el desarrollo de productos químicos, medicamentos, alimentos y cosméticos son áreas donde los experimentos con animales son legalmente requeridos. El modelo de gestión de animales de laboratorio se puede resumir como supervisión gubernamental y gestión de certificación de terceros. El pilar central de la supervisión gubernamental es el sistema de licencias y el sistema de certificación. China también ha establecido un sistema de auto-supervisión para instituciones de animales de laboratorio, como monitoreo y revisión ética. En el futuro, debería continuar mejorando el sistema existente y fortaleciendo la aplicación de la ley.

Palabras clave: animales de laboratorio; régimen jurídico; bienestar animal. 
As of 2017, according to statistics from scholars, the number of national laboratory animal licenses totaled 1,448. 1,382 units had been licensed in China. The 1,563 questionnaires showed that 1,392 submitters had established their laboratory animal management committees, accounting for $89 \%$. There were 1,320 review committees for laboratory animal welfare ethics, accounting for $84 \%{ }^{1}$ By 2018 , the number of laboratory animal license units reached 2114, a year-on-year increase of $52 \%{ }^{2}$ The number of laboratory animals has also risen rapidly in recent years with an annual increase of $15 \%{ }^{3}$ The annual output reached 20 million in $2017 .{ }^{4}$ In Guangdong for example, in 2016, 1.57 million laboratory animals were raised throughout the province, including 80,000 non-human primate laboratory animals, 754,000 laboratory animals were used throughout the year, and more than 6,000 cynomolgus monkeys were exported. The use of laboratory animals in Hubei Province increased by $32.3 \%$ in $2016 .{ }^{5}$ The scale of individual enterprises is also increasing. For example, Suzhou Xishan Zhongke Laboratory animal Co., Ltd. has more than 10,000 crab-eating monkeys, and rhesus monkeys are close to 2,000. ${ }^{6}$ Although China's laboratory animal industry is developing rapidly, it will need 100 years for the Chinese industry to reach the current level of the U.S. ${ }^{7}$ Therefore, China is vigorously developing the construction of laboratory animal resources.

The coronavirus pandemic has shaken the world since the end of 2019. On February 15, 2020, the Ministry of Science and Technology issued the "Guidelines on Strengthening the Biosafety Management of High-level Virus Microbiology Laboratory of New Crown Virus," which further aggravated many people's doubts about the incomplete legal system of laboratory animal management in China. Does China have a legal system for laboratory animal management? A detailed review of the existing laws shows that China has established the core concepts of laboratory animal management laws and initially established a legal system for laboratory animal management, but there are still issues such as relatively rough legislation and insufficient levels of protection standards. The future development path should be to strengthen the daily supervision of laboratory animal institutions and strengthen the law enforcement capabilities of relevant departments.

\section{Legal Concept System for Laboratory Animals}

Currently, China has formulated a series of regulations and standards on laboratory animals, and established a core legal concept system for laboratory animals.

\subsection{Laboratory animals}

China's regulatory documents enumerate the main animal names in the definition of laboratory animals in addition to the "Interim Regulations on the Management of Laboratory Animals in the Health System"(1983). ${ }^{8}$ According to other legal documents, laboratory animals are defined as those individuals that are "captive bred, in environments where microorganisms are controlled, having a traceable genetic background or source of origin, bred for scientific, teaching, production, testing and other research purposes." 9 "Source" refers to genetic background and microbial control. ${ }^{10}$

\footnotetext{
* In the writing of this paper, my master's student SuDa helped me retrieve the material and proofread and translate it.

${ }^{1}$ WANG, X., GONG, W., HE, Z., LI, G., Investigation on The Current Situation of Laboratory Animals Units, Personnel and Facilities in Mainland China [J]. Laboratory Animal Science 3 (2017) 66-70.

${ }^{2}$ LI, H., WANG, X., YANG, J., WEN, J., HUANG, R., CHEN, M., Current status and analysis of the Chinese laboratory animal license administration in 2018 [J]. Chinese Journal of Comparative Medicine 7 (2019) 131-136.

${ }^{3}$ China National Science and Technology Infrastructure Center. Investigation and Development Trend of Laboratory Animal Resources in China [M]. Science Press (2017).

${ }^{4} \mathrm{KONG}$, Q., Research on the development and present situation of laboratory animal industry in China [J]. Chinese Journal of Comparative Medicine 5 (2017) 19-22.

${ }^{5}$ YANG, W., WU, X., LU, H., LAI, Y., WANG, L., ZHANG, J., TANG, L., Investigation on the current situation of experimental animal resources in Hubei Province in 2016 [J]. Journal of Public Health and Preventive Medicine 5 (2019) 114-117.

${ }^{6}$ WU, K., Establishing a Public Service Platform for Animal Experiments - Xishan Zhongke Experimental Animal Co., Ltd.[J]. Sunan Sci-Tech. Devel. 12 (2007) 21-22.

${ }^{7}$ KONG, Q., XIA, X., ZHAO, Y., Analysis of laboratory animal strain resources in USA [J]. Acta Laboratorium Animals Scientia Sinica 5 (2015) 539-542.

${ }^{8}$ See Article 3 of the "Interim Regulations on the Management of Laboratory Animals in the Health System" issued by the Ministry of Health in 1983 stipulates that the laboratory animals referred to in these regulations include chickens, rats, and mice used in scientific research, medical treatment, teaching, inspection, and preventive medicine, Gophers, guinea pigs, rabbits, dogs, cats, monkeys, pigs, and other laboratory-grown wild animals. See Article 3 of the "Interim Regulations on the Management of Laboratory Animals in the Health System" (1983): http://www.law-lib.com/law/law_view.asp?id=2739

${ }^{9}$ See "The Regulations for the Administration of Laboratory Animals" (1988): https://www.lasen.net/Item/14.aspx.

${ }^{10}$ See "Implementing Rules for the Management of Medical Laboratory Animals" (1998):

https://www.lawxp.com/statute/s853566.html.
} 
It goes without saying that laboratory animals for research and teaching are worthy of special explanation in China. One reason is that the scale is getting larger; another is that the scope of application is very wide. The Chinese medicine industry has attracted much attention or controversy because it uses a large number of laboratory animals. The "Pharmacopoeia of the People's Republic of China"(2010) stipulated that biopharmaceutical companies need to use animal experiments in the pyrogen and abnormal toxicity inspection of biological products, as well as some injectables, biological products' pressure-boosting and depressurizing substance inspections, etc. In addition to this, there are many biological products that derive their raw materials from the organs of animals. ${ }^{11}$

\subsection{Animal welfare}

The concept of animal welfare was first seen in "Several Opinions on the Development of Laboratory animals During the Ninth Five-Year Plan" (1997). ${ }^{12}$ This was perhaps one of the first Chinese official documents that mentioned the concept. Although no definition was given on this new concept, the Opinions did introduce the 3R principle, i.e., "Replacement, Reduction, Refinement". The document touches on the state of complete psychological and physiological health of animals and their environment in the process of production and use of laboratory animals, important areas of animal well-being. ${ }^{13}$ In the "Quality Control Requirements for Laboratory Animals" (2017), this concept was expressed more precisely as "The sum of human's ideas of safeguarding the rights of laboratory animals to live healthily and happily and the corresponding external conditions." ${ }^{14}$ The implication of animal welfare also includes the mental heath aspect, which can be very difficult to evaluate precisely, with "Treating laboratory animals well" oriented as a possible solution.

"Treating laboratory animals well" means that "in the process of breeding, management, and use of laboratory animals, effective measures must be taken to protect laboratory animals from unnecessary harm, hunger, thirst, discomfort, panic, torture, disease and pain, and to ensure that animals can exhibit natural behavior." "Further, "Humans should use appropriate measures to protect the welfare of laboratory animals and avoid unnecessary harm." 16 This also includes the use of gentle means when capturing animals and the placement of recreational items such as toys when animals are transported. Primates are not allowed to be sacrificed in principle. After the experiment, they are kept alone until they die naturally.

\subsection{Cruelty to laboratory animals}

In Chinese legal documents, there are detailed provisions on "Cruelty to laboratory animals", including:

1. Harassment, beating, electric shock, use of irritating foods, chemicals, or drugs to harm laboratory animals not for experimental purposes;

2. Intentional damage to laboratory animal organs, not for experimental purposes;

3. Deterioration of the environment in laboratory animal facilities due to negligence, causing serious injury, suffering or death to laboratory animals;

4. Failure to perform anesthesia or other pain-relief measures on laboratory animals during anatomy, surgery or organ transplantation;

5. Execution of laboratory animals without euthanasia;

6. Violation of the provisions of the Guiding Opinions during the transportation of animals causing serious injury or a large number of deaths to laboratory animals;

7. Others situations that violate the basic principles for treating laboratory animals or violate the provisions of the Guiding Opinions. ${ }^{17}$

\footnotetext{
11 Chinese Pharmacopoeia Commission. Pharmacopoeia of the People's Republic of China[M]. China Medical Science and Technology Press (2010).

${ }^{12}$ See "Several Opinions on the Development of Laboratory animals During the Ninth Five-Year Plan " (1997):

https://www.lascn.net/Item/16.aspx.

${ }^{13}$ See "Guideline of assessment for humane endpoints in animal experiment" (2018): https://www.lascn.com/Item/75841.aspx

${ }^{14}$ See "Quality Control Requirements for Laboratory Animals" (2017):

http://www.baidu.com/link?url=q9X3qQTpgd0Sqs_Pf_Ww3giTwYCOKt1IN2CvPfXAlHg90Sk5ZIcve7WMOXbWOE1g\&wd=\&e qid=e37f573500009779000000055e7b0de1

${ }^{15}$ See "Guiding Opinions on Treating Laboratory animals" (2006): https://www.lascn.com/Item/49.aspx.

${ }^{16}$ See "Laboratory animal-Nomenclature" (2017): https://www.lascn.com/Item/70950.aspx.

${ }^{17}$ See "The Guiding Opinions on the Treatment of Laboratory animals" (2006) : http://pkulaw.cn/CLI.4.110620.

32 Derecho Animal. Forum of Animal Law Studies, vol. 11/2
} 


\section{The scope of application of the legal system for laboratory animals 2.1. Legal field of animal experiments}

Animal experiments are widely used in the research and development of chemicals, medicines, foods, and cosmetics. The requirements for animal tests stipulated by laws and regulations include research and development, registration, and other programs.

The Ministry of Health's "Technical Specifications for Chemical Toxicity Identification" (2005) stipulates the toxicological testing procedures, items, and methods for chemical toxicity identification. Chemical identification consists of four stages, all of which use animal testing methods. ${ }^{18}$

Regulations on food and food additives follow the Ministry of Health "Food Safety Toxicology Evaluation Procedure (Trial)" (1988). The toxicological evaluation procedure also has four stages using animal testing. ${ }^{19}$ For foreign companies to sell veterinary drugs in China, they must be registered, and relevant clinical trials and residue testing methods must be verified at designated institutions in China ${ }^{20}$ For foreign pharmacopoeia, veterinary pharmacopoeia, paid pharmacopoeia, or feed regulations, or where the government's drug administration in the producing country (region) has approved the production and sale, but it does not contain the Chinese pharmacopoeia, veterinary pharmacopoeia, veterinary drug specifications and professional standards, it is necessary to carry out a medicinal effect test, and the medicinal effect test is performed on animals. ${ }^{21}$

\subsection{Laboratory animals for research}

University medical schools also make extensive use of laboratory animals in daily teaching. Teaching in the fields of medicine, veterinary medicine, and other fields involves a lot of teaching content. The use of laboratory animals is very common, involving many animal species. At present, in addition to following national and relevant local legislation, this area mainly relies on the internal management system of universities. For example, China Medical University has formulated the "Measures for the Management of Laboratory animals." 22 Other schools have also introduced their own management methods, such as the "Measures for the Management of Laboratory animals at Southwest Medical University." ${ }^{23}$ Guangzhou Medical University also issued "Notice of Raising Laboratory animals" in which it was found that the results of teaching and research, experiments, tests, and evaluations in violation of this regulation are invalid, and the relevant research projects are not allowed to be accepted, identified, and evaluated. ${ }^{24}$

\section{Governmental management system for laboratory animals 3.1. Management system of laboratory animals}

The management model of laboratory animals in China can be summarized as government supervision and third-party certification management. The core pillar of government supervision is the license system and the certificate system. The core of the "Measures for the Management of Laboratory animals" (1991) promulgated by the National Medicines Administration was the license system. ${ }^{25}$ Since then, Guangdong and other provinces have promulgated local regulations, thereby establishing a comprehensive government supervision and management system.

The third-party certification management has a shorter history. Certification and Accreditation Administration of the People's Republic of China (CNCA) issued the "Laboratory Animal InstitutionsGeneral Requirements for Quality and Competence" (2014), establishing standards that are in line with

\footnotetext{
${ }^{18}$ See "Technical Specifications for Chemical Toxicity Identification" (2005): http://www.moh.gov.cn/public/open.aspx?n_id=10179.

${ }^{19}$ See "Food Safety Toxicology Evaluation Procedure (Trial)" (1988): http://pkulaw.cn/CLI.4.34010.

${ }^{20}$ See "Measures for the Registration of Veterinary Drugs" (2004): http://pkulaw.cn/CLI.4.56162.

${ }^{21}$ Art 40 of the "Implementing Rules and Regulations on Veterinary Drug Administration"(1988) stipulates that veterinary drugs exported to China for the first time by foreign companies must apply for registration with the Ministry of Agriculture and obtain the Import Veterinary Drug Registration License. Accordingly, Articles 9 and 10 of the "Administrative Measures for Registration and Administration of Veterinary Drugs in China by Foreign Enterprises" (1988) further stipulate in detail the documents that must be submitted to apply for an import veterinary drug registration license. See "Implementing Rules and Regulations on Veterinary Drug Administration" (1988): http://pkulaw.cn/CLI.4.8232 ; "Administrative Measures for Registration and Administration of Veterinary Drugs in China by Foreign Enterprises" (1988): http://www.110.com/fagui/law_112245.html

${ }^{22}$ Website of Laboratory Animal Department, China Medical University: http://www.cmu.edu.cn/sydwb/info/1834/1171.htm.

${ }^{23}$ Website of Experimental Animal Center of Southwest Medical University: http://dwzx.swmu.edu.cn/info/1108/1161.htm.

${ }^{24}$ Website of Experimental Animal Center of Guangzhou Medical University:

https://sydwzx.gzhmu.edu.cn/_local/B/E7/1E/17599A8E693CA71554DB40D8308_E675E304_2BB84.pdf?e=.pdf.

${ }^{25}$ See "Measures for the Management of Laboratory animals" (1991): http://pkulaw.cn/CLI.4.5120.
} 
international standards, ${ }^{26}$ and then released supporting standards ${ }^{27}$ and industry standards. ${ }^{28}$ Subsequently, the establishment of the accreditation and evaluation system for laboratory animal institutions was officially launched in 2018.

China implements a laboratory animal management system that combines unified supervision and management with departmental division of responsibilities. The State Scientific and Technological Commission is in charge of laboratory animals nationwide, while relevant functional departments are responsible for laboratory animals in their respective departments. ${ }^{29}$ The functional departments related to animal use in research are mainly the Health Commission and the Ministry of Agriculture. In view of the weak supervision and management of university laboratories, the Ministry of Education should take responsibility for this. National standards on genetics, microbiology, nutrition, and environment of laboratory animals are formulated by the State Technical Supervision Bureau. ${ }^{30}$

\subsection{A hierarchical management system}

Laboratory animals are divided into four grades in China: ordinary animals; clean animals; pathogenspecific animals; and sterile animals. Based on this, different requirements are raised for the animals' feeding environment, food and drinking water.

Laboratory animal breeding rooms and laboratories should be strictly separated. Laboratory animals of different grades, breeds, strains, and different experimental purposes shall be kept and managed separately in accordance with corresponding standards. The feed, cages, bedding, and drinking water of laboratory animals should meet national standards and relevant requirements. Experiments should be carried out using laboratory animals based on the corresponding grade standards and the purpose of the experimental application. Experiments on animals of different breeds or grades or experiments that can interfere with each other must not be conducted in the same laboratory. ${ }^{31}$

\subsection{License and Certificate system}

The Ministry of Science and Technology promulgated the "Administrative Measures for Laboratory Animal Licenses (Trial)" (2001), which stipulates that the laboratory animal production license is applicable to organizations engaged in the conservation, breeding, production, supply, transportation, and related commercial operations of laboratory animals and related products and personnel. The laboratory animal use license is applicable to organizations and individuals who use laboratory animals and related products for scientific research and experiments. ${ }^{32}$ Since then, some provinces have formulated specific measures to further refine the issuance of licenses. ${ }^{33}$

The main problem in license review and issuance is that the standards are not clear enough, and standards are not available on some laboratory animals such as cattle, geese, pigeons, etc. The science and technology authorities often issue licenses with reference to agricultural standards, which brings greater arbitrariness to the management of laboratory animals. After the State Council streamlined the license

\footnotetext{
${ }^{26}$ See "Laboratory animal institutions-General requirements for quality and competence" (2014):

https://www.lascn.com/Item/12693.aspx.

${ }^{27}$ See "Requirements of identification systems in laboratory animal institution" (2018):

http://www.biaozhuns.com/archives/20180818/show-193320-151-1.html ; "Guideline of assessment for humane endpoints in animal experiment" (2018): https://www.lascn.net/Item/75841.aspx.

${ }^{28}$ See "Laboratory animal-Guideline for euthanasia" (2017): https://www.lascn.net/Item/76486.aspx.

${ }^{29}$ See Art 4 of "Regulation on the Administration of Laboratory Animals" (2017): http://pkulaw.cn/CLI.2.293192. Laboratory animal management agencies include: (1) the State Drug Administration, a deputy ministerial-level national bureau administered by the State Administration of Market Supervision. Responsible for the registration, safety and risk supervision of drugs and cosmetics. (2) Administration of Traditional Chinese Medicine. It is a sub-ministerial national bureau affiliated to the National Health and Health Commission.

${ }^{30}$ See Art 7 of "Regulation on the Administration of Laboratory Animals" (2017): http://pkulaw.cn/CLI.2.293192.

${ }^{31}$ See Article 10 of the "Administrative Measures for Laboratory animals of Sichuan Province" (2019):

http://kjt.sc.gov.cn/bmxxgk/xxgkcontent.html?pt=T\&i=20191101111759-750433-00-000.

${ }^{32}$ See "Administrative Measures for Laboratory Animal Licenses (Trial)" (2001):

http://www.most.gov.cn/fggw/dffggw/dffgah/200703/t20070320_53901.htm.

${ }^{33}$ For example, Article 4 of the "Administrative Measures for the Management of Laboratory Animal Licenses in Beijing" (2017) stipulates that: engaged in the conservation, breeding, production, supply, transportation, or experiment of related products such as laboratory animals and experimental animal-specific feeds, cage appliances, bedding, etc. Units or individuals engaged in commercial animal operations shall obtain the "Labor Animal Production License". In 2011, Shanxi Province promulgated the "Implementation Rules for the "Administrative Measures on Laboratory Animal Licenses (Trial)" (2011). See "Administrative Measures for the Management of Laboratory Animal Licenses in Beijing" (2017): https://www.lascn.net/Item/11982.aspx ; "Implementation Rules for the "Administrative Measures on Laboratory Animal Licenses (Trial)" (2011): https://www.lascn.net/Item/5977.aspx. 
application review process, the Ministry of Science and Technology issued the "Implementation Plan for the Reform of Separation of Licenses and Certificates for Laboratory Animals in Free Trade Zones" in December 2019, eliminating more than 10 types of supporting materials (including information materials related to the applicant and other information materials related to the management of experimental animals) that need to be submitted when applying for a license, in order to improve the efficiency of administrative review, though this may also create loopholes for review. ${ }^{34}$

The main problems in the implementation of the license system are insufficient coverage and unclear standards. Some universities' laboratories often do not receive permits. Shanxi Province specifically issued a notice for this to require the full implementation of the license system. However, only Shanxi Medical University, out of 11 universities in the province, has obtained a license to use animals, and all other schools use laboratory animals in scientific research and teaching experiments without a license, indicating that this phenomenon is very common in China. ${ }^{35}$

The biggest problem in the implementation of this system is the over-emphasis on license management and the neglect of daily supervision. There is insufficient management of relevant departments regarding the implementation of issued licenses. License renewals also take the form of written reviews. The lack of supervision of the holder's management and care of laboratory animals, and the provision of the "Implementation Plan" further simplifies the review of renewals, which inevitably opens loopholes for wrongdoers.

Health administration in China has implemented certificates of qualification since 1992, including six types: qualification certificate for breeding technicians, qualification certificate for animal experiment technicians, qualification certificate for production and supply of laboratory animals, qualification certificate for animal experimental conditions, and quality certificate for laboratory animals. ${ }^{36}$ After 1995, the national certificate format was unified. ${ }^{37}$ Generally it is a triplicate, which is collected by the buying unit, selling unit, and management department.

Laboratory animal certificates for the Agricultural administration include certificate of laboratory animal quality, certificate of laboratory facility conditions, and certificate of feed.

\subsection{Archives and credit management system}

According to relevant national regulations, the management system of animal experiment files is an indispensable legal system for establishing animal laboratories. ${ }^{38}$

A laboratory animal health monitoring file management system should be established in the laboratory animal facility in accordance with relevant national regulations. The archives are kept for three years. ${ }^{39}$ At present, China has established a digital archive information system for laboratory animals.

The laboratory animal management system in China is designed to facilitate the management of laboratory animal institutions. The system uses software and hardware technology to handle the management of animal sources record keeping, animals booking for experiment, card opening, storage reservation, animal surgery scheduling, and an animal experiments information platform.

For example, Beijing has established a Laboratory Animal Information Management System (LAIMS). LAIMS is a laboratory animal management cloud platform built under the B / S infrastructure using advanced scientific and technological means to help Beijing's laboratory animal production and use units perform daily management. Important functions in this system include application functions such as laboratory animal file management, license management, quality certificate management, laboratory animal welfare ethics review management, and animal experiment management. They provide accurate data support for dynamic data analysis in the production and use of laboratory animals in Beijing. ${ }^{40}$

In addition, Article 29 of the "Measures for the Management of Laboratory animals in Sichuan Province" (2019) stipulates that: "Ministry of Science and Technology ${ }^{41}$ has established a credit management

\footnotetext{
${ }^{34}$ See "Implementation Plan for the Reform of Separation of Licenses and Certificates for Laboratory Animals in Free Trade Zones" (2019): http://www.gov.cn/xinwen/2019-11/30/content_5457130.htm.

${ }^{35}$ PANG, W., XU, G., CHEN, Z., SONG, G., The Current Situation and Recommendations in Laboratory Animal of Shanxi Province [J]. Laboratory Animal and Comparative Medicine 1 (2019) 61-64.

36 The China Ministry of Health. Measures for the Administration of Qualification Certificates of the Medical Laboratory Animal Management Committee of the Ministry of Health [J]. Chinese Journal of Laboratory Animal Science 4 (1994) 254-256.

${ }^{37}$ Medical Laboratory Animal Management Committee of Ministry of Health. Notice on the implementation of laboratory animal certification system in the national medical and health system [J]. Chinese Journal of Laboratory Animal Science 4 (1994) 252.

${ }^{38}$ See "Laboratory animals - General requirements for animal experiment" (2018): https://www.lascn.com/Item/70998.aspx.

${ }^{39}$ See "Laboratory animals - General guidelines for health monitoring" (2017): https://www.lascn.com/Item/71004.aspx.

${ }^{40}$ See Website of LAIMS: http://www.ilaims.com/.

${ }^{41}$ The Ministry of Science and Technology of the People's Republic of China is the department of the State Council responsible for national science and technology work.
} 
system for laboratory animal institutions and has made their credit information available to society, which anyone can request. ${ }^{42}$ A digital archive management system has also been established.

\section{Laboratory animal institution self-regulation legal system 4.1. Quality monitoring system}

Laboratory animal quality control refers to management activities that meet the requirements of national standards for laboratory animal quality. China currently implements laboratory animal health monitoring. It refers to quality control measures to detect whether laboratory animals meet the health requirements, including health screening of laboratory animals before entering the facility and monitoring and control of changes in health conditions in the facility. ${ }^{43}$ Laboratory animal health monitoring effectively monitors infectious pathogens such as microorganisms, parasites, and environmental and nutritional factors that may affect the health of laboratory animals. The time points for laboratory animal health monitoring include periodic sampling of animal groups in the facility before the animals are introduced into the facility, and timely inspection of suspected abnormal animals. ${ }^{44}$

All fields and units related to laboratory animals, such as research, conservation, breeding, supply, use, testing, and animal experiments, must conduct quality control of laboratory animals. Uniform quality management of laboratory animals is implemented throughout the country. ${ }^{45}$ Units engaged in laboratory animal breeding must monitor the quality of laboratory animals in accordance with relevant standards and record them truthfully and comprehensively.

The quality control of laboratory animals and related products shall be performed in accordance with national standards; if national standards have not been formulated, industry standards shall prevail. If neither of the above types of standards exist, local standards shall prevail. Quality testing should be based on standards in genetics, parasitology, microbiology, nutrition, and production environment facilities. ${ }^{46}$

Laboratory animal quality inspection institutions are managed at the national and provincial levels. Laboratory animal testing institutions at all levels take the national standard "General requirements for the competence of calibration and inspection laboratories" as the standard. ${ }^{47}$

Quality monitoring should be based on standards in genetics, parasitology, microbiology, nutrition, and production environment facilities. ${ }^{48}$ Animal laboratories should formulate standard operating procedures (SOPs) and related management regulations that are applicable with animal experimental work. ${ }^{49}$

\subsection{Ethical review system}

China has established a basic ethical review system for the use of laboratory animals. In addition to the ethical approval of laboratory animal research programs, the changes in the specific welfare environment and facilities must be reviewed by a review committee. Specifically, "the unit engaged in laboratory animal work shall establish a laboratory animal management group responsible for the management and ethical review of laboratory animal projects. Those that do not have such a group shall entrust other management organizations to conduct project management and ethics review and report annually to Ministry of Science and Technology on matters within its responsibility." 50

In 2018, China issued the guideline of assessment for humane endpoints in animal experiments. In line with international practices, China has formulated standards that are relatively advanced for China to guide and promote current work. There are three principles of determining the humane end point. The principle of trade-off requires the trade-off between the scientific value obtained from the experiment and the harm to the animal; the principle of minimization of harm requires that, as far as possible, the trial will predict the level of pain to the animal or the degree of pain. To the maximum extent, animal dying, death, and severe pain and

\footnotetext{
${ }^{42}$ See Article 29 of the "Administrative Measures for Laboratory animals of Sichuan Province" (2019): http://kjt.sc.gov.cn/bmxxgk/xxgkcontent.html?pt=T\&i=20191101111759-750433-00-000.

${ }^{43}$ See "Guiding Opinions on Treating Laboratory animals" (2006): https://www.lascn.com/Item/49.aspx.

${ }^{44}$ See "Laboratory animals - General guidelines for health monitoring" (2017): https://www.lascn.com/Item/71004.aspx.

${ }^{45}$ See Art 3 of "Laboratory animal quality management measures": http://www.pkulaw.cn//CLI.4.20963.

${ }^{46}$ See Article 6 of the "Administrative Measures for Laboratory Animals of Jiangsu Province" (2008) : https://www.lascn.net/Item/1054.aspx.

${ }^{47}$ See Art 18 of "Laboratory animal quality management measures": http://www.pkulaw.cn//CLI.4.20963.

${ }^{48}$ See Art 18 of "Administrative Measures for the Management of Laboratory Animal Licenses in Beijing” (2017): https://www.lascn.net/Item/11982.aspx

${ }^{49}$ See Art 5 of "Laboratory animals - General requirements for animal experiment" (2018): https://www.lascn.com/Item/70998.aspx.

${ }^{50}$ See Art 16 of the "Administrative Measures for Laboratory animals of Sichuan Province" (2019): http://kjt.sc.gov.cn/bmxxgk/xxgkcontent.html?pt=T\&i=20191101111759-750433-00-000.

36 Derecho Animal. Forum of Animal Law Studies, vol. 11/2
} 
suffering should be avoided as humane endpoints to ensure that the harm to animals is minimized. The principle of continuous optimization is to continue to seek more humane methods on the premise of achieving the scientific purpose of animal experiments. The end point of animal experiments keeps the pain experienced by animals in the course of use constantly minimized. The experimenter shall work with the veterinarian and other personnel to develop a humane end point plan for each animal and submit it to the Institutional Animal Care and Use Committee (IACUC) for review before the experiment. ${ }^{51}$

\subsection{Risk assessment and risk control system}

Animal laboratories shall establish and maintain a risk assessment and risk control system, continuously implement specific requirements for risk identification, risk assessment and risk control, and analyze and evaluate the identified risks in a risk assessment report which should at least cover an introduction to animal experiment activities (project plan), evaluation purposes, evaluation basis, evaluation methods, evaluation content, conclusions of animal experiment welfare ethics review, and evaluation conclusions. The protection of animal experiments adopts corresponding risk control measures based on the conclusions of risk assessment, including personnel protection, animal protection, environmental protection, etc. When taking risk control measures, it is advisable to first consider controlling animal and pathogenic hazards, then reducing risks, adopting appropriate protective equipment. ${ }^{52}$

\subsection{Biosafety management systems}

Units engaged in laboratory animal work shall establish and improve biosafety management systems, prevent and control laboratory infections, and prevent experiments that may endanger human health, public safety, and environmental safety in accordance with the relevant provisions of the "Animal Epidemic Prevention Law of the People's Republic of China" (2015). Animal escape and pathogen spread pathogen infection, chemical poisoning, and radiological animal experiments shall comply with the requirements of laws, regulations and national standards such as "Regulation on the Bio-safety Management of Pathogenic Microbe Labs" (2018) and national standards for laboratory biological safety, radiation health protection, and environmental protection to prevent accidents. Any person or organization that conducts genetic engineering research on laboratory animals must also comply with the corresponding laws and regulations. ${ }^{53}$

\subsection{Emergency management system}

Common laboratory emergencies include power failures, fires, water leaks, explosions, theft or destruction of important materials. Although China's "Technical Specifications for the Construction of Laboratory Animal Facilities" (2008) has detailed regulations on the construction of animal laboratories, in extreme cases, major biosafety accidents may occur. ${ }^{54}$ If a laboratory animal dies from a disease, the cause should be promptly ascertained, handled properly, and recorded. Laboratory animals suffering from infectious diseases must be immediately euthanized or quarantined separately, as appropriate, and reported to the local animal quarantine, health and anti-epidemic unit and the Ministry of Science and Technology to take emergency precautions to prevent the spread of the disease. In the case of zoonotic diseases, strict medical and clinical observations should be carried out on relevant personnel. In the case of a major animal epidemic, an emergency response plan should be initiated immediately in accordance with national regulations. ${ }^{55}$

\subsection{Group and enterprise self-public supervision system}

An enterprise shall disclose the numbers and names of the mandatory standards, recommended standards, group standards, or enterprise standards that it implements. When an enterprise implements its own enterprise standards, it shall also disclose the functional indicators of products and services and the performance indicators of products. The state encourages group standards and enterprise standards to be disclosed to the public through a standard information public service platform. An enterprise shall organize

\footnotetext{
${ }^{51}$ See "Guideline of assessment for humane endpoints in animal experiment" (2018): https://www.lascn.com/Item/75841.aspx.

${ }^{52}$ See "Laboratory animals - General requirements for animal experiment" (2018): https://www.lascn.com/Item/70998.aspx.

${ }^{53}$ See Article 22 of the "Administrative Measures for Laboratory animals of Sichuan Province" (2019):

$\mathrm{http} / / / \mathrm{kjt} . \mathrm{sc}$. gov.cn/bmxxgk/xxgkcontent.html?pt=T\&i=20191101111759-750433-00-000.

${ }^{54}$ See "Architectural and technical code for laboratory animal facility" (2008)

: http://www.jianbiaoku.com/webarbs/book/12310/712441.shtml

55 See Article 23 of the "Administrative Measures for Laboratory animals of Sichuan Province" (2019):

http://kjt.sc.gov.cn/bmxxgk/xxgkcontent.html?pt=T\&i=20191101111759-750433-00-000.
} 
its production and operation activities in accordance with standards, and the products and services it provides shall meet the technical requirements of open standards for enterprises. ${ }^{56}$

\section{Conclusion}

In order to obtain accurate, reliable, and reproducible research results, as well as international mutual recognition of research results, laboratory animal management has become the pioneering field in China to establish systems in the legal system of animal management and protection. So far, China has formed a complete set of legal rules for laboratory animals. These legal rules mainly focus on quality control and laboratory animal welfare. The system of quality management standards (QMSs) has been built through imitating other countries and regions, particularly Europe. It sets standards for laboratory animals' production condition, quality, and experimental conditions for animals, etc. In the process, the concept of animal welfare extracted and purified from those standards was applied in the legal system step by step. When concerning the legal aspects of ethical review or emergency management, the welfare of laboratory animals has been regarded as a special and key issue. For example, executing animals without using euthanasia is cruelty to animals. This sort of animal welfare promotion also shows that the protection and welfare of laboratory animals has become a global issue and is being put forward with globalization. Of course, there are still some systematic weaknesses in China, and the relevant regulations need to be perfected. The outbreak of COVID19 has brought a wide range of biosecurity and animal protection issues to the attention of Chinese lawmakers and the public, which will be a good opportunity to improve animal management and protection legislations and then strengthen their enforcement.

\section{References}

- China National Science and Technology Infrastructure Center. Investigation and Development Trend of Laboratory Animal Resources in China [M]. Science Press (2017)

- Chinese Pharmacopoeia Commission. Pharmacopoeia of the People's Republic of China [M]. China Medical Science and Technology Press (2010)

- KONG, Q., Research on the development and present situation of laboratory animal industry in China [J]. Chinese Journal of Comparative Medicine 5 (2017) 19-22

- KONG, Q., XIA, X., ZHAO, Y., Analysis of laboratory animal strain resources in USA [J]. Acta Laboratorium Animals Scientia Sinica 5 (2015) 539-542

- LI, H., WANG, X., YANG, J., WEN, J., HUANG, R., CHEN, M., Current status and analysis of the Chinese laboratory animal license administration in 2018 [J]. Chinese Journal of Comparative Medicine 7 (2019) 131-136

- Medical Laboratory Animal Management Committee of Ministry of Health. Notice on the implementation of laboratory animal certification system in the national medical and health system[J]. Chinese Journal of Laboratory Animal Science 4 (1994) 252

- PANG, W., XU, G., CHEN, Z., SONG, G., The Current Situation and Recommendations in Laboratory Animal of Shanxi Province[J]. Laboratory Animal and Comparative Medicine 1 (2019) 61-64

- The China Ministry of Health. Measures for the Administration of Qualification Certificates of the Medical Laboratory Animal Management Committee of the Ministry of Health[J]. Chinese Journal of Laboratory Animal Science 4 (1994) 254-256

- WANG, X., GONG, W., HE, Z., LI, G., Investigation on The Current Situation of Laboratory Animals Units, Personnel and Facilities in Mainland China [J]. Laboratory Animal Science 3 (2017) 66-70

- WU, K., Establishing a Public Service Platform for Animal Experiments - Xishan Zhongke Experimental Animal Co., Ltd. [J]. Sunan Sci-Tech.Devel 12 (2007) 21-22

- YANG, W., WU, X., LU, H., LAI, Y., WANG, L., ZHANG, J., TANG, L., Investigation on the current situation of experimental animal resources in Hubei Province in 2016 [J]. Journal of Public Health and Preventive Medicine 5 (2019) 114-117

- Interim Regulations on the Management of Laboratory Animals in the Health System (1983): http://www.law-lib.com/law/law_view.asp?id=2739

- Administrative Measures for Registration and Administration of Veterinary Drugs in China by

${ }^{56}$ See "Standardization Law of the People's Republic of China" (2017): http://www.pkulaw.cn/CLI.1.304266.

38 Derecho Animal. Forum of Animal Law Studies, vol. 11/2 
Foreign Enterprises (1988): http://www.110.com/fagui/law 112245.html

- Food Safety Toxicology Evaluation Procedure (Trial) (1988): http://pkulaw.cn/CLI.4.34010.

- Implementing Rules and Regulations on Veterinary Drug Administration (1988): http://pkulaw.cn/CLI.4.8232

- The Regulations for the Administration of Laboratory Animals (1988): https://www.lascn.net/Item/14.aspx.

- Measures for the Management of Laboratory animals (1991): http://pkulaw.cn/CLI.4.5120.

- Several Opinions on the Development of Laboratory animals During the Ninth Five-Year Plan (1997): https://www.lascn.net/Item/16.aspx.

- Implementing Rules for the Management of Medical Laboratory Animals (1998): https://www.lawxp.com/statute/s853566.html.

- Administrative Measures for Laboratory Animal Licenses (Trial) (2001): http://www.most.gov.cn/fggw/dffggw/dffgah/200703/t20070320_53901.htm.

- Measures for the Registration of Veterinary Drugs (2004): http://pkulaw.cn/CLI.4.56162.

- Technical Specifications for Chemical Toxicity Identification (2005): http://www.moh.gov.cn/public/open.aspx?n_id=10179.

- Guiding Opinions on Treating Laboratory animals (2006): https://www.lascn.com/Item/49.aspx.

- Administrative Measures for Laboratory Animals of Jiangsu Province (2008): https://www.lascn.net/Item/1054.aspx.

- Architectural and technical code for laboratory animal facility (2008): http://www.jianbiaoku.com/webarbs/book/12310/712441.shtml.

- Implementation Rules for the Administrative Measures on Laboratory Animal Licenses (Trial) (2011): https://www.lascn.net/Item/5977.aspx.

- Laboratory animal institutions-General requirements for quality and competence (2014): https://www.lascn.com/Item/12693.aspx.

- Administrative Measures for the Management of Laboratory Animal Licenses in Beijing (2017): https://www.lascn.net/Item/11982.aspx

- Laboratory animal - Nomenclature (2017): https://www.lascn.com/Item/70950.aspx.

- Laboratory animals - General guidelines for health monitoring (2017): https://www.lascn.com/Item/71004.aspx.

- Laboratory animal - Guideline for euthanasia (2017): https://www.lascn.net/Item/76486.aspx.

- Quality Control Requirements for Laboratory Animals (2017): http://www.baidu.com/link?url=q9X3qQTpgd0Sqs_Pf_Ww3giTwYCOKt1IN2CvPfXAlHg90Sk5 ZIcve7WMOXbWOE1g\&wd=\&eqid=e37f573500009779000000055e7b0de1

- Regulation on the Administration of Laboratory Animals (2017): http://pkulaw.cn/CLI.2.293192.

- Standardization Law of the People's Republic of China (2017): http://www.pkulaw.cn/CLI.1.304266.

- Guideline of assessment for humane endpoints in animal experiment (2018): https://www.lascn.com/Item/75841.aspx

- Laboratory animals - General requirements for animal experiment (2018): https://www.lascn.com/Item/70998.aspx.

- Requirements of identification systems in laboratory animal institution (2018): http://www.biaozhuns.com/archives/20180818/show-193320-151-1.html

- Administrative Measures for Laboratory animals of Sichuan Province (2019): http://kjt.sc.gov.cn/bmxxgk/xxgkcontent.html?pt=T\&i=20191101111759-750433-00-000.

- Implementation Plan for the Reform of Separation of Licenses and Certificates for Laboratory Animals in Free Trade Zones (2019): http://www.gov.cn/xinwen/2019-11/30/content_5457130.htm.

- Laboratory animal quality management measures: http://www.pkulaw.cn//CLI.4.20963.

- Website of Laboratory Animal Department, China Medical University: http://www.cmu.edu.cn/sydwb/info/1834/1171.htm.

- Website of Experimental Animal Center of Southwest Medical University: http://dwzx.swmu.edu.cn/info/1108/1161.htm.

- Website of Experimental Animal Center of Guangzhou Medical University: https://sydwzx.gzhmu.edu.cn/_local/B/E7/1E/17599A8E693CA71554DB40D8308_E675E304_2 BB84.pdf? $=$.pdf.

- Website of LAIMS: http://www.ilaims.com/. 